A\&L

ISSN 2709-0205

Vol 1 Issue 1 (2020)

Review

\title{
Age peculiarities of pharmacokinetics and pharmacodynamics of medicines
}

\author{
L.P. Kuprash ${ }^{1}$, S.A. Gudarenko', O.V. Kuprash ${ }^{1}$, N. A. Gorchakova ${ }^{2}$, O.V. Khodakivska ${ }^{2}$ \\ ${ }^{1}$ State Institution “D. F. Chebotarev Institute of Gerontology NAMS of Ukraine”, Kyiv, Ukraine \\ ${ }^{2}$ The Bogomolets National Medical University, Kyiv, Ukraine
}

Correspondence: kuprash@geront.kiev.ua

Received: 20.12.2019; Accepted: 05.02.2020; Published: 07.07.2020

\begin{abstract}
The drug therapy of elderly and senile patients is characterized by a number of features due to morphological, metabolic and functional disorders that occur in the body during aging at all levels of the body's life activity: the molecular genetic level, cellular level, the organ level, the regulatory level. As a result, the drugs' pharmacokinetics and pharmacodynamics of drugs change which has a significant impact on the effectiveness and safety of drug therapy in elderly and senile patients
\end{abstract}

Keywords: Drug therapy, pharmacokinetics of medicines, pharmacodynamics of medicines, aging.

With age, the main elements of drug pharmacokinetics - absorption, distribution, biotransformation and elimination - change significantly $[1,2,3,4]$.

As a result of structural and functional changes in the digestive system during aging, the absorption of drugs prescribed internally is disrupted [5, 6].

The absorption in the gastrointestinal tract during aging is characterized by a decrease of the suction surface, reduced motility, delayed evacuation, decreased secretory activity, and decreased blood flow in mesenteric vessels, which leads to slower absorption [5]. The weakening of intestinal motility and slowing down the evacuation capacity of the stomach in elderly people are very important [3]. Therefore, a number of drugs enter the body of elderly people in a slightly smaller amount and more slowly than in young patients [7].

As a result of reducing the amount of gastric juice in old people, the absorption of drugs in the stomach that are chemically acids - salicylates, barbiturates, nitrofurans, anticoagulants and some sulfonamides - decreases. It not only slows down their entry into the blood and reduces the therapeutic effect, but also as a result of a longer stay in the stomach, causes an irritating effect on its mucous membrane, which is accompanied by dyspeptic phenomena and pain in the epigastric region, and it can also lead to the formation of ulcers in the stomach, gastric bleeding $[8,9]$.

In the aging process the volume of distribution of drugs decreases due to decrease in the pumping function of the heart, impaired tissue microcirculation, reduction of water spaces of the body, the fat depot $[3,10]$.

The reduction of water spaces leads to the decrease in the volume of hyd rophilic drugs distribution and the increase in their concentration in blood plasma and tissues, which increases the risk of overdose and drug intoxication. It refers to aminoglycoside antibiotics, cardiac glycosides, betablockers, and calcium channel blockers [11].

The increase in the amount of adipose tissue in the older age contributes the increased volume of distribution and decreased concentrations of lipophilic drugs in tissues, which is accompanied by a 
slower start and longer duration of action. It refers to tetracyclines, benzodiazepine tranquilizers, phenothiazine neuroleptics, and barbiturates [11].

The important aspect of the distribution of the drug in the body is its binding to plasma proteins, since only an unbound drug can diffuse into the tissue or be excreted from the body. The aging of the body is accompanied by the decrease in the content of albumins in the blood plasma by an average of 10$15 \%$. Hypoalbuminemia leads to the decrease in the bound fraction of the drug and the increase in the concentration of the free fraction which increases the effectiveness of the drug, as well as increases the possibility of overdose, toxic and adverse reactions. The concentration of many drugs in plasma in elderly patients increases significantly, sometimes reaching a toxic level, especially in drugs with a small therapeutic margin. It is especially important for drugs that have a high degree of binding to plasma proteins (more than $80 \%$ ) - beta-blockers, sulfonamides, salicylates, cardiac glycosides, benzodiazepine tranquilizers, indirect anticoagulants, antidiabetic agents, narcotic analgesics, anticonvulsants [12, 13].

A significant role in age-related changes in the pharmacokinetics of drugs is the decrease of systems activity in the process of aging, these systems perform their biotransformation, primarily the decrease of the activity of microsomal liver enzymes- monooxydase (cytochrome P450), aminopyrin-ndemethylase, and hexobarbital hydroxylase [14, 15].

When studying liver biopsies in patients older than 70 years, the content of cytochrome P450 was $32 \%$ lower than in patients aged 20-29 years, after 40 years the concentration decreased by an average of $0.07 \mathrm{nmol} / \mathrm{g}$ per year [16].

Along with it, the activity of the second phase of hepatic biotransformation of drugs conjugation - decreases in old age [4].

Slowing down the metabolism of drugs with age contributes to a longer-term maintenance of their therapeutic concentrations in the tissues of the old body. First of all, it refers to drugs that are actively metabolized in the liver - neurotropic drugs, beta-blockers, cardiac glycosides, non-steroidal antiinflammatory drugs, anticoagulants. Taking into account the age-related decrease in the induction of microsomal oxidation enzymes, special care is required to prescribe these groups of drugs to elderly and senile patients in association with medications of microsomal enzyme inducers which include barbiturates, tranquilizers, spironolactone, rifampicin, and others [7, 10, 17].

With age kidney function decreases, renal blood flow and glomerular filtration decreases which determines to a large extent the slowing of renal elimination of drugs in the senile body. The glomerular filtration rate measured by endogenous creatinine clearance is reduced by $35-50 \%$ in the elderly [18].

The decrease in renal function leads to the concentration increase of drugs that are excreted unchanged, and active or toxic metabolites, as well as increases the half-life, creating a risk of drug accumulation, overdose, and side effects [11].

Age-related changes of the main components of drug pharmacokinetics -absorption, distribution, biotransformation, and elimination - lead to the decrease in the clearance of most drugs in the elderly and senile age and the extension of their half-life $[4,7]$.

Therefore, it is necessary to correct doses of drugs for elderly patients with a small margin of therapeutic action: cardiac glycosides (strofantin, corglikon, digoxin), aminoglycoside antibiotics, as well as cephalosporins, antidiabetic, antiarrhythmic, diuretic agents, clonidine, non-steroidal antiinflammatory drugs. Prescribing a standard adult dose to an elderly patient may lead to a disproportionately high serum content of the drug [19].

The level of the antibiotics concentration in the blood of older people is higher than in young people. The accumulation of antibiotics in the body leads to the development of undesirable reactions, whose number increases with age from $11.8 \%$ at the age of 40 to 45 years to $24 \%$ at the age of more than 80 years, so it is recommended to lengthen the intervals between their administration in patients of older age groups [20].

Along with age-related changes in pharmacokinetics, with aging the pharmacodynamics of different drug groups changes due to alterations in the number of farmacoreceptors, their sensitivity to drugs, as well as changes in the metabolites content, activity of enzymes, the reactions of the internal environment of the body, the reactivity of the nervous system [21, 22, 23, 24].

So, in the process of aging, the number of beta-adrenergic receptors in tissues decreases, their sensitivity to stimulating and blocking effects changes which causes the frequency of complications 
(bradycardia, hypotension,) when prescribing this group of drugs to patients older than 60 years. The use of beta-blockers in patients of older age groups requires considerable caution [25, 26].

With age, the sensitivity of baroreceptors increases. Therefore, when calcium antagonists are prescribed to older patients, orthostatic hypotension may develop due to a sharp decrease in blood pressure which dictates the need to prescribe lower doses of the drug [27, 28].

With age the sensitivity to the action of anticoagulants increases. At the same time due to agerelated hypoalbuminemia in old age, the fraction of drugs associated with albumins decreases and the concentration of the free fraction in the blood plasma increases which dictates the need to prescribe these drugs to patients of older age groups in smaller doses [29, 30, 31].

In case of the glycosidotherapy in elderly patients, complications are often observed due to the increase in the sensitivity of the old heart to the action of glycosides because of age-related metabolic changes in the myocardium (electrolyte composition, acid-base balance, activity of membrane-bound enzymes, in particular, transport ATPases which are considered specific receptors for cardiac glycosides on the plasma membrane of cardiomyocytes). Therefore, the administration of cardiac glycosides to elderly and senile patients requires special attention (the drug selection, the dose determination, the concomitant therapy) [32]. When taking diuretics, patients of older age groups lose more fluid than young ones, they have more pronounced hypokalemia, hypouricemia, hypovolemia, dehydration with azotemia. According to various authors, adverse reactions during diuretic therapy in older people are observed in 6-12\% [33].

As a result of age-related changes of the central nervous system, disturbances in the processes of excitation and inhibition in old age, sensitivity to narcotic and hypnotic drugs is significantly increased [17].

In consequence of age-related changes in the dopaminergic system (the decrease in endogenous dopamine levels and the decrease in the density of dopamine receptors), sensitivity to antipsychotic agents increases with age [34, 35].

When prescribing tricyclic antidepressants for older patients, the anticholinergic, sedative, and cardiovascular side effects are often observed [36, 37].

Age-related changes in the pharmacokinetics and pharmacodynamics of drugs increase the risk of adverse reactions in elderly and senile patients which is particularly dangerous in conditions of agerelated polypragmasia [11, 17]. Increasing the frequency and severity of chronic disease raises the level of polypragmasia, reaching more than 6-7 drugs per patient in patients of older age groups [38, 39, 40,41].

The consequence of polypragmasia in older patients is the increase in the risk of adverse reactions as a result of drug interactions $[42,43]$. The frequency and severity of adverse reactions in drug interactions correlates with age and the number of prescribed medications [44, 45].

Adverse reactions in the interaction of drugs develop both at the stage of transport and metabolism (pharmacokinetic interaction) and at the level of pharmacoreception (pharmacodynamic interaction). Among the adverse reactions registered in elderly patients with diseases of the circulatory system, $64.9 \%$ were developed due to pharmacokinetic interaction, $20.1 \%$ - due to pharmacodynamics one, and $15.0 \%$ of the mechanisms of drug interaction were not established [41].

Special attention in the treatment of elderly and senile patients must be paid to undesirable reactions that occur during pharmacokinetic interaction in the process of drug biotransformation. Due to the age-related decrease in the activity of cytochrome P450, the blood concentration of drugs actively metabolized by this enzyme increases significantly which is accompanied by the risk of adverse reactions, especially when inhibitors of this cytochrome are prescribed simultaneously [46].

Thus, the metabolism of the beta-blockers of metoprolol, propranolol, and carvedilol occurs with the participation of cytochrome P450. The prescription of these drugs simultaneously with enzyme inhibitors (amiodarone, cimetidine, antidepressants) to elderly patients increases the risk of bradycardia (less than 40 beats/min), and atrioventricular block. The optional drug may be atenolol which is not metabolized by liver enzymes and is excreted unchanged [47].

Cytochrome P450 metabolizes the oral anticoagulant warfarin. Simultaneous prescription of warfarin and inhibitors of this cytochrome (amiodarone, some antibiotics) is a common cause of adverse reactions in elderly patients [15]. 
Predictable pharmacodynamic interaction is widely used in combination therapy of various diseases. In particular, combinations of ACE and diuretics, ACE and calcium channel blockers, angiotensin II receptor blockers and diuretics are effective in the treatment of hypertension in elderly patients $[48,49,50]$.

At the same time, the pharmacodynamic interaction can lead to the decrease in the effectiveness of drug therapy and the development of undesirable side reactions, which requires special attention to the choice of individual drugs [51, 52, 53, 54,55].

The decrease in the effectiveness of ACE inhibitors in elderly patients with simultaneous prescription of non-steroidal anti-inflammatory drugs was found [30].

A number of authors note a significant incidence of hyperkalemia in elderly patients with simultaneous administration of ACE and potassium-preserving diuretics [54, 55].

The simultaneous prescription of beta-blockers and hypoglycemic drugs may increase the effect of the latter and lead to the development of hyperglycemic coma in patients of older age groups [53].

Age-related changes in the pharmacodynamics and pharmacokinetics of drugs significantly reduce the effectiveness and safety in old age [56].

\section{Conclusion}

In order to optimize drug therapy for elderly and senile patients it is necessary to prescribe to patients individually reduced doses especially of those drugs that increase sensitivity with aging. Taking into consideration the slowing down of drug metabolism and the lengthening of their half-life in old age, it is necessary to increase the intervals between the drug administration. When prescribing several drugs, it is necessary to consider their possible interaction and its effect on the course of the disease.

It is necessary to proceed from the features of pharmacokinetics and pharmacodynamics of specific groups of drugs.

Author Contributions: All authors participated equally in writing this commentary.

Conflicts of Interest: The authors declare no conflict of interest.

Information about Authors:

Liana P. Kuprash - DSc (Medicine), Head of the Geriatric Pharmacology Laboratory of the State Institution "D. F. Chebotarev Institute of Gerontology NAMS of Ukraine"; https://orcid.org/ 0000-0001-8196-751X

Svetlana A. Gudarenko - Researcher of the Laboratory of Geriatric Pharmacology of the State Institution “D. F. Chebotarev Institute of Gerontology NAMS of Ukraine"

Olena V. Kuprash - MD, PhD (Medicine), Department of Clinical and Epidemiological Cardiology of the State Institution

"D. F. Chebotarev Institute of Gerontology NAMS of Ukraine"

Nadiya O. Gorchakova - DSc (Medicine), Prof. of the Department of Pharmacology with a course in clinical pharmacology of the Bogomolets National Medical University

Olena V. Khodakivska - MD, PhD (Medicine), Bogomolets National Medical University 


\section{References}

1. Hammerlein, A.; Derendorf, H.; Lowenthal, D. Pharmacokinetic and Pharmacodynamic Changes in the Elderly. Clinical Pharmacokinetscs 1998, 35, 49-64.

2. Klotz, U. Pharmacokinetics and drug metabolism in the elderly. Drug Metabolism Reviews 2009, 41, 2, 67-76.

3. Shi, S.; Klotz, U. Age-Related Changes in Pharmacokinetics. Current Drug Metabolism 2011, 12, 7, 601-610.

4. Cusack, B.J. Pharmacokinetics in older persons. Am J Geriatr Pharmacother 2004, 2, p 274-302.

5. Warren, P.; Pepperman, M. Montgomery R. Age changes in small-intestinal mucosa. Lancet 1978, 2, 849-850.

6. Abrams William, B. A discussion of nutrient effects on drug metabolism and action in the elderly. Drug-Nutr. Interact. 1985, 4, 1-2, 209-215.

7. Sadeanmd, M.R.; Glassmd, P.S.A. Pharmacokinetics in the elderly. Clinical Anaesthesiology 2003, 17(2), 191-205.

8. Divoll, M; Ameer, B.; Abernethy, D. et al. Age does not alter acetaminophen absorption. Am. Geriatr. Soc. 1982, 20, 1, 240-244.

9. Moore, J.; Tweedy, C.; Christian P. Effect of age on gastric emptying of liquid solid meals in man. Dig. Dis. Sci. 1983, 28, 340-344.

10. Hutchison, L.C.; O'Brien, C.E. Changes in Pharmacokinetics and Pharmacodynamics in the Elderly Patient. J Pharmacy Practice 2007, 20, 1, 4-12.

11. Corsonello, A.; Pedone, C. Antonelli Incalzi R. Age-Related Pharmacokinetic and Pharmacodynamic Changes and Related Risk of Adverse Drug Reactions. Current Medicinal Chemistry 2010, 17, 571-584.

12. Greenblatt, D. Reduced serum albumin concentration in the elderly: report from the Boston Collaborative Drug Surveillance Program. J. Am. Geriatr. Soc. 1979, 27, 301-312.

13. Guay, D.; Artz, M.; Hunlon, J. et al. The pharmacology of aging. In Textbook of geriatric Medicine, Tailis, R.; Fillith, H., Ed. Churchill: N-Y., 2003, 155-161.

14. Sotaniemi, E.; Arranto, A.; Pelkonen, O. et al. Age and cytochrome P450-linked drug metabolism in humans: An analysis of 2.26 subjects with equal histopathologic conditions. Clin. Pharmacol. Ther. 1997, 61, 331-339.

15. Cabrera, M.A.; Dip, R.M.; Furlan, M.O.; Rodrigues S.L. Use of drugs that act on the cytochrome P450 system in the elderly. Clinics 2009, 64, 4 p 273.

16. Schmucker, D.; Woodhouse, K.; Wang, R. et al. Effects of age and gender on in vitro properties of human liver microsomal monooxygenases. Clin. Pharm. Ther. 1990, 48, 365- 374.

17. Ginsberg, G.; Hattis, D.; Russ, A.; Sonawane B. Pharmacokinetic and Pharmacodynamic Factors That Can Affect Sensitivity to Neurotoxic Sequelae in Elderly Individuals. Environ Health Perspect 2005, $113,1243-1249$.

18. Lindeman, R. Changes in renal function with aging: Implications for treatment. Drags Aging 1985, 2, 423-431.

19. Greenblatt, D.J.; Sellers, E.M.; Shader R.I. Drug disposition in old age. N Engl J Med 1982, 306, p 1081.

20. Grieco, M. Use of antibiotics in the elderly. Bull NY. Acad. Med. 1980, 56, 2, 197-208.

21. Trifiro, G.; Spina, E. Age-related Changes in Pharmacodynamics: Focus on Drugs Acting on Central Nervous and Cardiovascular Systems. Current Drug Metabolism 2011, 7, 12, 611-620.

22. Wynne, H. Drug metabolism and ageing. J Br Menopause Soc. 2005, 11,2, 51-56.

23. Thurmann, P.A. Pharmacodynamics and pharmacokinetics in older adults. Curr Opin Anaesthesiol 2020, 33, 1, 109-113.

24. Vuykmd, J. Pharmacodynamics in the elderly. Best Practice \& Research Clinical Anastheology 2003, $17,2,207-218$.

25. White, M.; Roden, R.; Minobe, W. et al. Age-related changes in beta-adrenergic neuroeffector systems in the human heart. Circulation 1994, 90, 1225-1238. 
26. Dobre, D.; Haaijer-Ruskamp F.M.; Voors, A.A.; van Veldhuisen, D.J. beta-Adrenoceptor antagonists in elderly patients with heart failure: a critical review of their efficacy and tolerability. Drugs Aging 2007, 24, 1031-1044.

27. Donnelly, R.; Elliott, H.L. Factors influencing the responses to calcium antagonists in elderly patients with hypertension and ischaemic heart disease. Exp. Gerontol. 1990, 25, 375-381;

28. Montamat, S.C.; Abernethy, D.R. Calcium antagonists in geriatric patients: Diltiazem in elderly persons with hypertension. Clin. Pharmacol. Ther. 1989, 45, 682-691.

29. Husted, S.; Andreasen, F. The influence of age on the response to anticoagulants. Brit. J. Clin. Pharmacol. 1977, 4, 559-565.

30. Wittkowsky, A.K.; Whitely, K.S.; Devine, E.B.; Nutescu, E. Effect of age on international normalized ratio at the time of major bleeding in patients treated with warfarin. Pharmacotherapy 2004, 24, 600-605.

31. Hylek, E.M.; Evans-Molina, C.; Shea, C. et al. Major hemorrhage and tolerability of warfarin in the first year of therapy among elderly patients with atrial fibrillation. Circulation 2007, 115, 2689-2696. 32. Kuprash, L.P. Age - related aspects of pharmacodynamics of cardiac glycosides. The 4 th Asia/Oceania regional congress of gerontology, Oct, 31. - Nov 3, 1991, Yokohama: Abstracts: Yokohama, 1991, p 390. 33. Baglin, A.; Boulard, J.C.; Hanslik, T.; Prinseau, J. Metabolic adverse reactions to diuretics. Clinical relevance to elderly patients. Drug Saf. 1995, 12, 161-167.

34. Uchida, H.; Mato, D.C.; Mulsant B.H. et al. Increased antipsychotic sensitivity in elderly patients: evidence and mechanisms. Journal of Clinical Psychiatry 2008, 70, 3, 397- 405.

35. Tune, L.E. Anticholinergic effects of medication in elderly patients. J Clin Psychiatry 2001, 62, 11-

14.

36. Sultana, J.; Spina, E.; Trifiro G. Antidepressant use in the elderly: the role of pharmacodynamics and pharmacokinetics in drug safety. J Expert Opinion on Drug Metabolism \& Toxicology 2015, 11, 6, 883-892.

37. Van Walraven, C.; Mamadani, M.M.; Wells, P.S.; Williams, J.I. Inhibition of serotonin reuptake by antidepressants and upper gastrointestinal bleeding in elderly patients: retrospective cohort study. $\mathrm{Br}$. Med. J. 2001, 323, 655-658.

38. Ali, A.N.; Armugam, A.; Leon, T.S. et al. Polypharmacy in elderly patients at discharge medication. IJPRD 2011, 3, 6, 1-9.

39. Pilotto, A.; Franceschi, M.; Niro, V. et al. Comorbidity and polypharmacy in elderly. J. Gerontol. 2005, 53, 57-62.

40. Nobili, A.; Garattini, S.; Mannucci, P.M. Multiple diseases and polypharmacy in the elderly: challenges for the internist of the third millennium. Journal of Comorbidity 2011, 1, 28-44.

41. Fulton, M.M.; Alien, E.R. Polypharmacy in the elderly: a literature review. J Am Acad Nurse Pract. 2005, 17, 123-132.

42. Patel, V.K; Acharya, L.D.; Rajakannan, T. et al. Potential drug interactions in patients admitted to cardiology wards of a south Indian teaching hospital. AMJ 2011, 4, 1, 9-14.

43. Petrovic, M.; van der Cammen, T.; Onder, G. Adverse drug reactions in older people: detection and prevention. Drugs Aging 2012, 29, 453-462.

44. Gujjarlamudi, H.B. Polytherapy and drug interactions in elderly. J Midlife Health 2016, 7, 3, 105107.

45. Kraehenbuehl, S. Polypharmazie im Alter. Der Informierte Arzt. 2012, 4, 34-37.

46. Sera, L.C.; McPherson, M.L. Pharmacokinetics and Pharmacodynamic Changes Associated with Aging and Implications for Drug Therapy. Clin Geriatr Med. 2012, 28, 2, 273-286.

47. Zakrzewski-Jakubiak, H.; Donn, J.; Lamoureux P. et al. Detection and prevention of drug-drug interactions in the hospitalized el utility of new cytochrome P450-based software. American Journal of Geriatric Pharmacotherapy 2011, 9, 6, 461-470.

48. Calhoun, D.A., Lacourcière, Y.; Chiang, Y.T.; Glazer, R.D. Triple Antihypertensive therapy with amlodipine, valsartan, and hydrochlorothiazide: a randomized clinical trial. Hypertension 2009, 54, 32-39. 49. Destro, M.; Crikelair, N.; Yen, J.; Glazer, R. Triple combination therapy with amlodipine, valsartan, and hydrochlorothiazide vs dual combination therapy with amlodipine and 
hydrochlorothiazide for stage 2 hypertensive patients. Vascular Health and Risk Management 2010, 6, 821827.

50. Kizilirmak, P.; Uresin, Ya.; Bulent, O. The efficacy and safety of triple vs dual combination of angiotensin II receptor blocker and calcium channel blocker and diuretic: A systematic review and metaanalysis. The Journal of Clinical Hypertension 2013, 15, 3, 193-200.

51. Khalil, H.; Najem, R.; Sison, J. et al. Real-world effectiveness of amlodipine/valsartan and amlodipine/valsartan/hydrochlorotiazide in high-risk patients and other subgroups. Vascular Health and Risk Management 2015, 11, 71-78.

52. Lin, C.F.; Wang, C.Y.; Bai, C.H. Polypharmacy, aging and potential drug-drug interactions in outpatients in Taiwan: a retrospective computerized screening study. Drugs Aging 2011, 28, 219-225.

53. Aparasu, R.; Baer, R.; Aparasu, A. Clinically important potential drug-drug interactions in outpatient settings. Res Social Adm Pharm. 2007, 3, 426-437.

54. Schepkens, H.; Vanholder, R.; Billiouw, J.M.; Lameire, N. Lifethreatening hyperkaliemia during combined therapy with angiotensin-converting enzyme inhibitors and spironolactone: an analysis of 25 cases. Am. J. Med. 2001, 110, 438-441.

55. Ahuja, T.S.; Freeman, D.Jr.; Mahnken, J.D. et al. Predictors of the development of hyperkalemia in patients using angiotensin-converting enzyme inhibitors. Am J Nephrol. 2000, 20, 268-272.

56. Chaurasia, R.N.; Singh, A.K.; Gambhir, I.S. Rational drug therapy in elderly. Journal of the Indian Academy of Geriatrics 2005, 1, 2, 82-88. 